ARTICLE

\title{
Elimination diets and dietary interventions for the management of food allergies
}

\author{
A C Lang, D A van der Spuy, E Goddard, A J Terblanche, M Kriel, C L Gray, S Karabus, A I Manjra, S M Risenga, M E Levin, \\ for the South African Food Allergy Working Group (SAFAWG)
}

All authors' degrees, affiliations and conflict of interest statements can be found online at http://dx.doi.org/10.7196/SAMJ.9201

Corresponding author: A Lang (alison@clinicaldiets.co.za)

The primary therapy for food allergy is strict avoidance of the offending food or foods. Dietary restriction should be tailored to meet the nutritional requirements of each patient. Patients should be educated on how to avoid allergens safely by understanding terminology for common ingredients and how to read food labels. Information regarding safe, cost-effective and freely available substitutes for the avoided foods should be provided. Patients should be re-evaluated at regular intervals to see if they have developed tolerance.

Mothers of infants with cow's milk protein allergy (CMPA) who are breastfeeding should be supported and encouraged to continue breastfeeding. Partially hydrolysed infant formulas are not hypoallergenic (tolerated by $90 \%$ of subjects with proven CMPA) and are therefore not recommended for the treatment of CMPA, but may have a role in prevention of eczema or CMPA in high-risk individuals.

Some extensively hydrolysed and amino-acid-based formulas are truly hypoallergenic. The recommended feed of choice for the dietary management of mild-to-moderate CMPA in infants not breastfed is an extensively hydrolysed cow's milk formula. The recommended formula for the dietary management of non-breastfed infants and children with known severe CMPA is an amino-acid-based formula. Soya-based formulas may be useful in infants with immunoglobulin E (IgE)-mediated CMPA with proven tolerance to soya, and some cases of mild-to-moderate non-IgE-mediated CMPA, bearing in mind the increased risk of co-reactivity between CMPA and soya allergy in nonIgE-mediated conditions. Other mammalian milks and plant-based milks, including rice and oat milks, are not suitable as sole nutrition for cow's milk protein allergic individuals.

S Afr Med J 2015;105(1):71-72. DOI:10.7196/SAMJ.9102

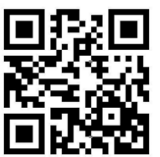

The primary therapy for food allergy is strict avoidance of the offending food or foods. ${ }^{[1]}$ This is true for both immunoglobulin E (IgE)- and non-IgEmediated food allergy.

Dietary restriction should be tailored to meet the nutritional requirements of each patient by a registered dietician who is experienced in food allergies. Regular contact with the healthcare professional is encouraged to adjust management, as tolerance may change over time and the child may outgrow the food allergy. ${ }^{[1]}$

\section{Assessment of nutritional status}

It is essential to assess the nutritional status of an infant or child both prior to and during nutritional intervention. ${ }^{[2]}$ The nutritional status of the child will also determine what food alternatives are appropriate. For example, if a child is milk and soya allergic but eats solids well and is thriving, rice milk could be considered as a milk alternative. If the child is malnourished, a well-formulated milk alternative with protein and iron becomes essential.

Food allergy may be the cause of faltering growth in young children. ${ }^{[3]}$ This may be directly due to malabsorption of nutrients as a result of an allergic enteropathy or indirectly due to extensive dietary restrictions without appropriate nutritious alternatives. A combination of these problems may also occur.

Single food avoidance is often straightforward. Multiple food restrictions usually have more nutritional challenges.

Factors like religion and vegetarian or vegan eating are important in the original assessment. For example, a vegetarian child allergic to egg and milk is far more at risk of nutritional deficiencies than a child who eats meat.

\section{Length of elimination period}

Patients need to be re-evaluated at regular intervals to see if they have developed tolerance. This varies depending on the individual foods and whether it is an IgE- or non-IgE-mediated food allergy. Generally younger children with milk, soya and egg allergy should be reviewed every $6-12$ months and older children every $1-2$ years. These allergies usually improve over time. Prolonged unnecessary avoidance may affect nutritional status and quality of life. Younger children need more regular monitoring as their diets change rapidly with increasing age.

For certain IgE-mediated food allergy (e.g. to tree nuts, fish and shellfish), length of exclusion may be lifelong but re-evaluation with skin-prick and $\operatorname{IgE}$ tests will determine whether rechallenges are appropriate or exclusion needs to be continued. This can be performed less frequently (every 2 - 4 years). ${ }^{[4]}$

\section{Education}

Education is the mainstay of dietary avoidance advice. Patients should be educated on how to avoid allergens safely by understanding terminology for common ingredients and how to read food labels. They should be made aware of risky situations and cross-contamination. Information regarding safe, cost-effective and freely available substitutes for the avoided foods should be provided. 'Free from' recipes may also be useful. When choosing alternatives it is important to consider the nutritional value, cost-effectiveness and availability of the substitute products.

\section{Nutrients at risk in avoiding common allergens}

- Milk: high-quality protein, calcium and riboflavin.

- Eggs: high-quality protein, vitamins $\mathrm{A}, \mathrm{B}_{12}, \mathrm{D}$, and $\mathrm{E}$, riboflavin, pantothenic acid, iron, selenium, biotin, lutein and iodine. 
- Legumes (including soya), nuts and seeds: protein, fibre and a range of vitamins and minerals.

- Seafood: high-quality protein, vitamins A, D and omega 3 fatty acids in oily fish.

\section{Cow's millk substitutes}

There are a variety of choices as alternative feeds for those with known cow's milk protein allergy (CMPA). Strong evidence is still lacking to guide the use of these formulas, as studies have been small and of low quality. Parents of infants and young children with CMPA should be counselled on the most appropriate formula or milk substitute to use, taking into consideration the type of reaction experienced, severity of reaction, age of the patient (need for formula as the sole or a significant part of their diet), religious and cultural views, and the cost and palatability of the feed.

\section{Breastfeeding}

Mothers of infants with CMPA who are breastfeeding should be supported and encouraged to continue breastfeeding. ${ }^{[5,6]}$ Although food allergens in the mother's diet are transmitted via breastmilk, they may be sufficiently modified to allow inclusion by the mother in varying amounts, as tolerated by the infant. ${ }^{[7]}$ In rare circumstances, an elimination diet will need to be followed by the mother, under dietary guidance to ensure nutritional adequacy. ${ }^{[8]}$ If cow's milk needs to be avoided by the mother, she needs to be on a calcium supplement to provide $1000 \mathrm{mg}$ (19 - 50 years of age) - $1300 \mathrm{mg}$ ( $\leq 18$ years of age) elemental calcium/day. ${ }^{\left[{ }^{[9}\right.}$

\section{Hydrolysed and elemental formulas} The classification of feeds as partially hydrolysed, extensively hydrolysed or elemental depends on the degree of hydrolysis and therefore the size of the resulting proteins or amino-acids.

\section{Partially hydrolysed formulas}

Partially hydrolysed infant formulas have not been proven to be hypoallergenic (tolerated by $90 \%$ of subjects with proven CMPA) and are therefore not recommended for the treatment of CMPA, ${ }^{[1]}$ but may have a role in prevention of eczema or CMPA in high-risk individuals. ${ }^{[10-12]}$

\section{Hypoallergenic formulae}

Some extensively hydrolysed and aminoacid-based formulas are truly hypoallergenic. Table 1 outlines the hypoallergenic formulas available in South Africa (SA).

\section{Extensively hydrolysed formulas}

The recommended feed of choice for the dietary management of mild or moderate CMPA in

Table 1. Commercially available hypoallergenic formulas

\begin{tabular}{lll}
\hline Product & Intended age & Description \\
\hline Amino-acid-based formulas & & \\
Neocate (Nutricia) & $<1$ year & Free amino-acid formula \\
Aminomed (Nutr-e-Volution) & $<1$ year & Free amino-acid formula \\
Neocate Advance (Nutricia) & $>1$ year & Free amino-acid formula \\
Comidagen plus (Nutr-e-Volution) & $>1$ year & Free amino-acid formula \\
Extensively hydrolysed formulas & & \\
Alfare (Nestle) & $<1$ year & Whey formula \\
Allernova Smooth (Novalac) & $<1$ year & Casein formula \\
Pepticate (Nutricia) & $<1$ year & Whey formula \\
Similac Alimentum (Abbott) & $<1$ year & Casein formula \\
Formulas specifically formulated for infants $<1$ year may be used in those $>1$ year as a supplemental feed in appropriate quantities.
\end{tabular}

infants not breastfed is an extensively hydrolysed cow's milk formula. The cow's milk protein in these formulas has been broken down to free amino-acids and peptides $<1500 \mathrm{kDa}$, which have been proven to be hypoallergenic. By definition these formulas are effective in the treatment of $90 \%$ of infants with CMPA. ${ }^{[1,5,13]}$

Both extensively hydrolysed casein- and wheybased formulas are available in SA (Table 1). The disadvantages of these formulas are the palatability, especially noticeable in infants older than 4 months of age, ${ }^{[14]}$ and higher cost.

\section{Amino-acid-based (elemental) formulas}

The recommended formula for the dietary management of non-breastfed infants and children with known severe CMPA is an amino-acid-based formula, ${ }^{[5,15]}$ which is the only completely non-allergenic formula.

Because of the high costs, an aminoacid-based formula has targeted use, and is specifically recommended for:

- infants with CMPA with severe or lifethreatening symptoms ${ }^{[1,5]}$

- patients with ongoing symptoms on an extensively hydrolysed formula ${ }^{[1]}$

- infants with severe growth faltering ${ }^{[1]}$

- in rare circumstances where a stringent exclusion diet in the breastfeeding mother has failed to resolve symptoms in the infant.

\section{Soya protein-based infant formulas}

Because of the cost constraints and poor taste acceptability in older infants of extensively hydrolysed formulas, soya protein-based infant formulas have often been given as a substitute for regular cow's milk formulas in milk-allergic infants in SA. ${ }^{[16]}$

Soya-based formulas may be useful in:

- Infants with IgE-mediated CMPA who have been proven to be tolerant to soya. ${ }^{[17]}$

- Some cases of mild-to-moderate non-IgEmediated CMPA, ${ }^{[18]}$ bearing in mind the increased risk of co-reactivity between CMPA and soya allergy in non-IgEmediated conditions. This should be done under close supervision.

Fears of harmful side-effects of phytooestrogens from soya-based infant formulas have not been proven in human studies. Further high-quality studies with statistical power are urgently needed before evidencebased recommendations can be made. ${ }^{[19-23]}$

\section{Other}

\section{Other mammalian milks}

- There is a high cross-reactivity between mammalian milks ${ }^{[1,5,24]}$ (e.g. goat, sheep, buffalo and others). For example, 95\% of children allergic to cow's milk protein react to goat's milk. ${ }^{[25]}$ These milks are not suitable for CMPA individuals.

- Alternative mammalian milks, including goat's and sheep's milk, have not been modified for human infants and are not nutritionally adequate for use as sole infant formula.

\section{Cereal milks}

Plant-based milks, including rice and oat milks, are not nutritionally adequate, as they contain inadequate protein, calcium and iron. They are therefore inappropriate as a sole infant formula. They may, however, be used as a substitute in older infants, children and adults in small amounts, provided their nutritional requirements are being met by the rest of the diet.

\section{Role of formula in prevention of food allergy}

A detailed description of allergy prevention is beyond the scope of this guideline. In respect of infant feeding: 
- Exclusive breastfeeding for 4 - 6 months is recommended for allergy prevention. The World Health Organization recommends 6 months' exclusive breastfeeding for nutritional and infectious disease outcomes.

- In high-risk infants (with a first-degree relative with allergy) who are unable to exclusively breastfeed, a partially or extensively hydrolysed formula of proven benefit may reduce the risk of allergy equivalent to (but not lower than) that for breastfed infants. ${ }^{[10,11,12]}$

- Soya milk and milks of other mammalian origin or plant origin have no role in prevention of CMPA.

\section{Probiotics}

Probiotics are defined as 'live microorganisms, which, when administered in adequate amounts, confer a health benefit on the host: ${ }^{[26]}$ Potential targets of probiotic effect in food allergy include prevention, treatment and tolerance induction. ${ }^{[27]}$ Probiotics show a moderate risk reduction for eczema in approximately half of all studies, especially those with both pre- and postnatal administration of probiotics; ${ }^{[28]}$ however, at present a role for probiotics in the prevention or treatment of food allergy is not established, ${ }^{[26,27]}$ and they should not be routinely prescribed.

\section{References}

1. EAACI Food Allergy and Anaphylaxis Guidelines: Diagnosis and management of food allergy (in EAACI Food Allergy and Anaphylaxis Guidelines: Diagnosis and management of food allergy (in
press). 2014. http://www.eaaci.org/component/content/article/724-latest-educational-resources/3156press). 2014. http://www.eaaci.org/component/content/article/724-latest-
food-allergy-anaphylaxis-guidelines.html (accessed 20 November 2014).

2. Isolauri E, Sütas Y, Salo MK, Isosomppi R, Kaila M. Elimination diet in cow's milk allergy: Risks for impaired growth in young children. J Pediatr 1998;132(6):1004-1009. [http://dx.doi.org/10.1016/ S0022-3476(98)70399-3]

3. Noimark L, Cox HE. Nutritional problems related to food allergy in childhood. Pediatr Allergy Immunol 2008;19(2):188-195. [http://dx.doi.org/10.1111/j.1399-3038.2007.00700.x]

4. Boyce JA, Assaad A, Burk AW, et al. Guidelines for the diagnosis and management of food allergy in the United States. J Allergy Clin Immunol 2010;126(suppl):S1-58. [http://dx.doi.org/10.1016/j.jaci.2010.10.008]

5. Koletzko S, Niggemann B, Arato A, et al., European Society of Pediatric Gastroenterology, Hepatology, and Nutrition (ESPGHAN). Diagnostic approach and management of cow's-milk protein allergy in infants and children: ESPGHAN GI Committee practical guidelines. J Pediatr Gastroenterol Nutr 2012;55(2):221-229. [http://dx.doi.org/10.1097/01.mpg.0000181841.07090.f4]

6. Centre for Clinical Practice at National Institute for Health and Clinical Excellence (NICE) (UK). Food Allergy in Children and Young People: Diagnosis and Assessment of Food Allergy in Children and Allergy in Children and Young People: Diagnosis and Assessment of Food Allergy in Children and
Young People in Primary Care and Community Settings. London: National Institute for Health and Young People in Primary Care
Clinical Excellence (UK), 2011.
7. Restani P, Gaiaschi A, Plebani A, et al. Evaluation of the presence of bovine proteins in human milk as a possible cause of allergic symptoms in breast-fed children. Ann Allergy Asthma Immunol 2000;84:353-360. [http://dx.doi.org/10.1016/S1081-1206(10)62786-X]

8. Du Toit G, Meyer R, Shah N, et al. Identifying and managing cow's milk protein allergy. Arch Dis Child Educ Pract Ed 2010;95:134-144. [http://dx.doi.org/10.1136/adc.2007.118018]

9. Institute of Medicine: Food and Nutrition Board. Dietary Reference Intakes for Calcium, Phosphorus Institute of Medicine: Food and Nutrition Board. Dietary Reference Intakes for Calcium,
Magnesium, Vitamin D and Fluoride. Washington, DC: National Academies Press, 1997.

Magnesium, Vitamin D and Fluoride. Washington, DC: National Academies Press, 1997.
10. Muraro A, Dreborg S, Halken S, et al. Dietary prevention of allergic disease in infants and small Muraro A, Dreborg S, Halken S, et al. Dietary prevention of allergic disease in infants and small
children. Part III: Critical review of published peer-reviewed observational and interventional studies and final recommendations. Pediatr Allergy Immunol 2004;15:291-307. [http://dx.doi.org/10.1111/ j.1399-3038.2004.00127.x

11. Osborn DA, Sinn J. Formulas containing hydrolysed protein for prevention of allergy and food intolerance in infants. Cochrane Database Syst Rev 2006;(4):CD003664. [http://dx.doi.org/10.1002/14651858. CD003664.pub2]

12. Alexander DD, Cabana MD. Partially hydrolyzed $100 \%$ whey protein infant formula and reduced risk of atopic dermatitis: A meta-analysis. J Pediatr Gastroenterol Nutr 2010;50:422-30. [http://dx.doi org/10.1097/MPG.0b013e3181cea52b]

13. American Academy of Pediatrics: Committee on Nutrition. Hypoallergenic infant formulas. Pediatrics 2000;106:346-349.

14. Mennella JA, Griffin CE, Beauchamp GK. Flavor programming during infancy. Pediatrics 2004;113:840-845. [http://dx.doi.org/10.1542/peds.113.4.840]

15. Burks AW, Tang M, Sicherer S, et al. ICON: Food allergy. J Allergy Clin Immunol 2012;129(4):906-920. [http://dx.doi.org/10.1016/j.jaci.2012.02.001]

16. Kattan JD, Cocco RR, Järvinen KM. Milk and soy allergy. Pediatr Clin North Am 2011;58(2):407-426. [http://dx.doi.org/10.1016/j.pcl.2011.02.005]

17. Dupont C, Chouraqui JP, de Boissieu D, et al. Dietary treatment of cows' milk protein allergy in childhood: A commentary by the Committee on Nutrition of the French Society of Paediatrics. Br J Nut 2012;107:325-338. [http://dx.doi.org/10.1017/S0007114511004831]

18. Kemp AS, Hill DJ, Allen KJ, et al. Guidelines for the use of infant formulas to treat cow's milk protein allergy: An Australian consensus panel opinion. Med J Aust 2008;188:109-112.

19. Dinsdale EC, Ward WE. Early exposure to soy isoflavones and effects on reproductive health: A review of human and animal studies. Nutrients 2010;2(11):1156-1187. [http://dx.doi.org/10.3390/nu2111156] 20. Patisaul HB, Jefferson W. The pros and cons of phytoestrogens. Front Neuroendocrinol 2010:31(4):400-419. [http://dx.doi.org/10.1016/.j.yfne.2010.03.003]

21. Vandenplas Y, de Greef E, Devreker T, Hauser B. Soy infant formula: Is it that bad? Acta Pædiatrica 2011;100:162-166. [http://dx.doi.org/10.1111/j.1651-2227.2010.02021.x]

22. Cederroth CR, Auger J, Zimmermann C, Eustache F, Nef S. Soy, phyto-oestrogens and male reproductive . Cederroth CR, Auger J, Zimmermann C, Eustache F, Nef S. Soy, phyto-oestrogens and male reproductive
function: A review. Int J Androl 2010;33:304-316. [http://dx.doi.org/10.1111/j.1365-2605.2009.01011.x] 23. McCarver G, Bhatia J, Chambers C, et al. NTP-CERHR Expert Panel Report on the Developmental Toxicity of Soy Infant Formula. Birth Defects Research (Part B) 2011;92:421-468. [http://dx.doi. Toxicity of Soy Infant
org/10.1002/bdrb.20314

24. Jarvinen KM, Chatchatee P. Mammalian milk allergy: Clinical suspicion, cross-reactivities and diagnosis Curr Opin Allergy Clin Immunol 2009;9:251-258. [http://dx.doi.org/10.1097/ACI.0b013e32832b3f33]

25. Fiocchi A, Brozek J, Schünemann H, et al. World Allergy Organization (WAO) Diagnosis and Rationale for Action against Cow's Milk Allergy (DRACMA) Guidelines. World Allergy Organ J 2010;3(4):57-161. [http://dx.doi.org/10.1097/WOX.0b013e3181defeb9]

26. Fiocchi A, Burks W, Bahna SL, et al. Clinical Use of Probiotics in Pediatric Allergy (CUPPA): A World Allergy Organization position paper. World Allergy Organ J 2012;5:148-167. [http://dx.doi. org/10.1097/WOX.0b013e3182784ee0]

27. Nermes M, Salminen S, Isolauri E. Is there a role for probiotics in the prevention or treatment of food allergy. Curr Allergy Asthma Rep 2013;13(6):622-630 [http://dx.doi.org/10.1007/s11882-013-0381-9]

28. Pfefferle PI, Prescott SL, Kopp M. Microbial influence on tolerance and opportunities for intervention with prebiotics/probiotics and bacterial lysates. J Allergy Clin Immunol 2013;131(6):1453-1463.
. [http://dx.doi.org/10.1016/j.jaci.2013.03.020] 